\title{
Large retroperitoneal hemangioma encompassing the renal vein
}

\author{
Matthew Mossanen, MD; Manjiri Dighe, MD; John Gore, MD; Gary Mann, MD
}

University of Washington Medical Centre, Department of Urology, Seattle, WA, U.S.

Cite as: Can Urol Assoc J 2015;9(11-12):E894-6. http://dx.doi.org/10.5489/cuai.3356 Published online December 14, 2015.

\section{Abstract}

Retroperitoneal hemangioma $(\mathrm{RH})$ is a rare and benign vascular malformation. RH may be detected incidentally or present with symptoms due to local invasion of adjacent structures. Management options include surgical resection, as well as serial observation with routine imaging. We describe a retroperitoneal hemangioma encompassing the renal vein that was discovered during diagnosis of acute appendicitis, and characterize diagnostic magnetic resonance imaging (MRI) findings seen with this condition.

\section{Case presentation}

A 26-year-old man with an unremarkable medical history presented to the emergency department with abdominal pain, nausea, and vomiting. His lab studies were notable for a mild leucocytosis. A computed tomography (CT) scan demonstrated findings consistent with acute appendicitis. The scan also revealed an incidental finding of a retroperitoneal mass encasing the renal vein measuring $3.9 \times 4.6 \times 5.5 \mathrm{~cm}$. The patient underwent an uneventful laparoscopic appendectomy and was discharged the following day without complications. Final pathology revealed vermiform appendix with suppurative transmural exudate and no neoplasm.

In order to further characterize the retroperitoneal mass, a CT-guided biopsy was performed at an outside hospital. The specimen demonstrated features consistent with a vascular neoplasm, most consistent with angioma including large ectatic vessels. Although small sample size precluded definitive characterization, the lesion was thought to be most consistent with a benign vascular malformation or hemangioma. For further followup, MRI was performed and indicated a retroperitoneal mass characteristic of a large, benign venous hemangioma originating

from the retroperitoneum and encasing the renal vein. The patient was asymptomatic and had a normal creatinine.
Management options were presented to the patient, including serial imaging, surgical resection, and repeat biopsy. He was counselled that removal of the mass would necessitate nephrectomy and the possibility of autotransplantation to avoid becoming reliant upon a solitary kidney. The patient was also counselled on the impact of this diagnosis on his ability to participate in living donor kidney transplantation. After he opted for active surveillance rather than surgical intervention, repeat imaging six months after the initial diagnosis revealed no substantial interval change. He opted to continue active surveillance with MRI followup at routine intervals. After two years of interval imaging without significant change in appearance or size, the patient was discharged from clinic. Here we describe clinical characteristics of this lesion and findings seen on MRI.

\section{Discussion}

\section{Etiology and demographics}

RHs are extremely rare tumours. ${ }^{1}$ In adults, the diagnosis of $\mathrm{RH}$ is confirmed in $1-3 \%$ of all retroperitoneal masses. ${ }^{2}$ Since 1950, there have been approximately 40 cases reported in the literature, of which five cases required surgical intervention due to local tumour growth. ${ }^{3}$ However, RH may rupture, resulting in life-threatening hemorrhage requiring emergent surgical exploration. ${ }^{4}$

\section{Clinical findings and differential diagnosis}

Patients may present with flank pain or hematuria. In most instances, patients lack clinical symptoms. No lab abnormalities are classically associated $\mathrm{RH}$. There is no apparent gender predisposition, ${ }^{5}$ and cases have been reported in both children ${ }^{6}$ and adults. ${ }^{3}$ Although classically a benign tumour, $\mathrm{RH}$ can be locally invasive of adjacent structures and lead to destruction of neighboring organs. ${ }^{3}$ This involvement of adjacent structures may induce symptoms that prompt presentation. Increased growth of hemangiomas has led to 


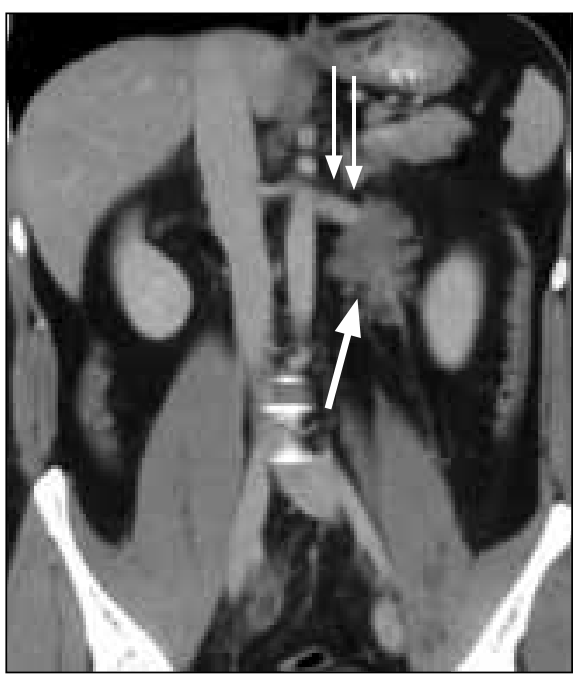

Fig. 1. Coronal reformat from the contrast CT scan shows a relatively hypovascular mass (arrow) in the left retroperitoneum medial to the left kidney, encasing the left renal vein (double arrows).

thrombosis and obstruction from inadequate venous drainage. ${ }^{7}$ The differential diagnosis for tumours of the retroperitoneum may include teratomas, liposarcomas, and leimyosarcomas. Cavernous hemangioma has also been reported to mimic a cystic renal cell carcinoma (RCC), leading to partial nephrectomy. ${ }^{8}$ In addition, malignant vascular tumours to be considered include eiptheleoid hemangioendothelioma and Kaposi's sarcoma. ${ }^{1}$

Due to the complexity of retroperitoneal anatomy, RHs often involve vital structures, making resection extremely technically challenging. ${ }^{9}$ The majority of available literature is derived from isolated case reports and small case series of no more than five patients. Reported surgical cases of RH have necessitated associated interventions, including nephrectomy, splenectomy, duodenectomy, and pancreatectomy. ${ }^{3}$ Among patients that have undergone partial or radical nephrectomy for renal $\mathrm{RH}^{10-13}$ pathologic specimens have revealed

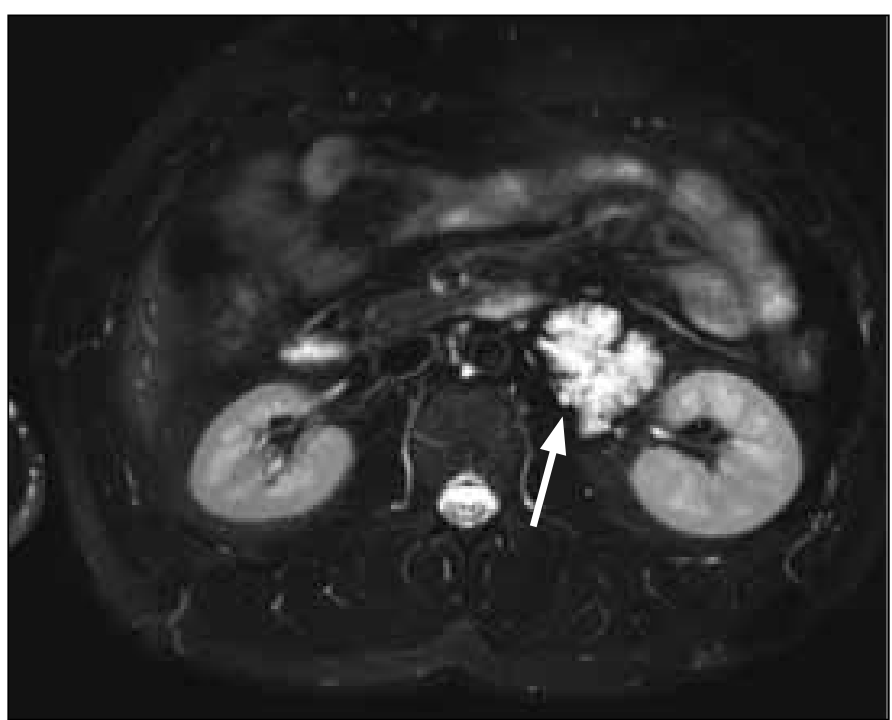

Fig. 2. Axial T2 fat-suppressed MR image shows the mass (arrow) to have a high-signal intensity compared to the adjacent kidney.

almost complete replacement by normal renal parenchyma with hemangioma. ${ }^{12}$ Positive immunostaining for CD31 and CD34 confirms endothelial origin and supports the diagnosis of hemangioma. ${ }^{3,4,14}$ Hemangiomas have been well-described throughout the genitourinary system, and have been reported in adrenal, ${ }^{4}$ renal, ${ }^{10,11,15}$ and testicular ${ }^{8}$ locations.

\section{Imaging}

MRI has been shown to aid in the diagnosis of RH. On T1 imaging, RHs may have low signal intensity, ${ }^{1}$ and on T2-weighted imaging, areas of high intensity within the tumour have been suggested to represent hemorrhage and hyalinization of tissue. ${ }^{3}$ CT scans have also been used for diagnosis and may show patchy intensity with a dense peripheral rim. ${ }^{4}$ Figure 1 demonstrates an image from the patient's CT scan and Figures 2 and 3 demonstrate selected MRI images.

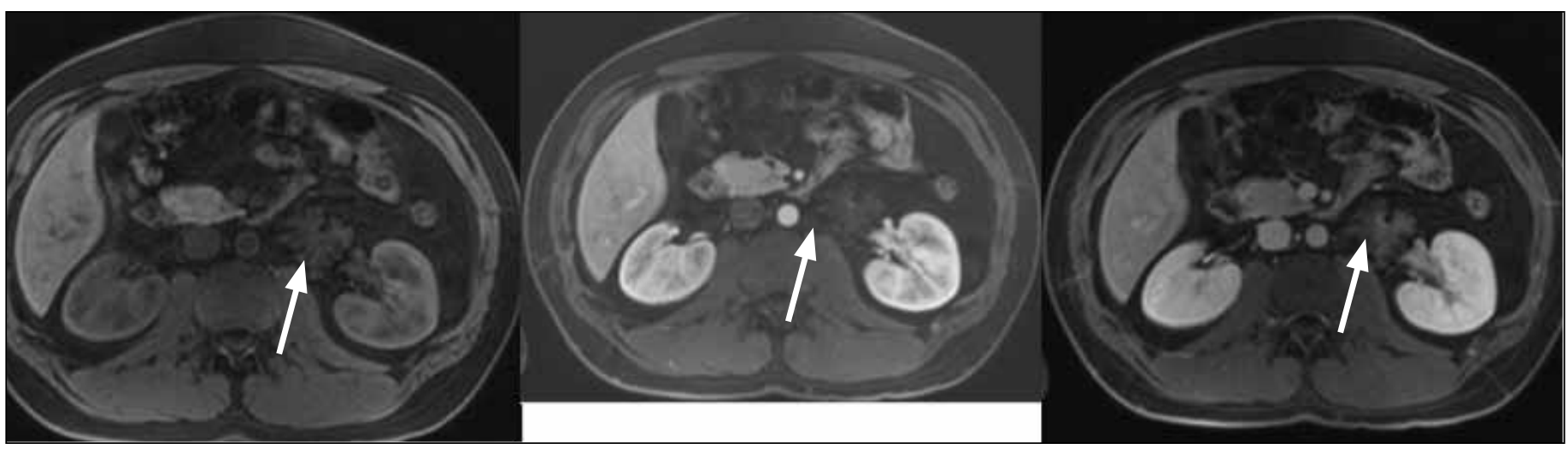

Figs. 3a-c: MR axial pre- (a), arterial- (b), and delayed- (c) phase images show gradual enhancement of the mass (arrow). There was no evidence of involvement of the adjacent kidney, however, the left renal vein was encased by the mass. 
Mossanen et al.

\section{Treatment}

Due to the rarity of the condition, there are no standard radiographic criteria to establish the diagnosis. During diagnostic evaluation of hemangiomas of renal origin, imaging techniques that have been shown to improve diagnostic accuracy include CT angiography, flexible ureteroscopy, angiograph with selective embolization, and excretory urography. ${ }^{12,16}$ However, with the advent of MRI, it is possible to follow these lesions serially and minimize radiation exposure associated with CT or plain radiography. ${ }^{17}$ Operative and non-operative approaches are possible for $\mathrm{RH}$ patients. Due to the complexity of surgical resection of these lesions, high-volume centres may offer optimal opportunities for surveillance and multidisciplinary care. ${ }^{9}$

\section{Conclusions}

Diagnosis of RH is confounded by the rarity of the condition in addition to the vascular anatomic diversity that may account for variety of potential presentations. The optimal management of RH has not yet been standardized, although options for patients include surveillance and surgical resection based on lesion location, size, growth over time, and symptomatology.

Competing interests: Dr. Mossanen and Dr. Gore declare no competing financial or personal interests. Dr. Dighe has received grants and/or honoraria from General Electric. Dr. Mann has received payment from Castle Biosciences.

This paper has been peer-reviewed.

\section{References}

1. Igarashi J, Hanazaki K. Retroperitoneal venous hemangioma. Am J Gastroenterol 1998;93:2292-3. http://dx.doi.org/10.1111/j.1572-0241.1998.00642.x

2. Braasch JW, Mon AB. Primary retroperitoneal tumours. Surg Clin North Am 1967;47:663-78.

3. Hanaoka M, Hashimoto M, Sasaki K, et al. Retroperitoneal cavernous hemangioma resected by a pylorus preserving pancreaticoduodenectomy. World I Gastroenterol 2013;19:4624-9. http://dx.doi. org/10.3748/wig.v19.i28.4624

4. Forbes TL. Retroperitoneal hemorrhage secondary to a ruptured cavernous hemangioma. Can I Surg 2005; $48: 78-9$.

5. He H, Du Z, Hao $S$, et al. Adult primary retroperitoneal cavernous hemangioma: A case report. World J Surg Oncol 2012;10:261. http://dx.doi.org/10.1186/1477-7819-10-261

6. Adam YG, Alberts W. Retroperitoneal hemangioma. Am Surg 1990;56:374-6.

7. Powis SJ, Rushton DI. A case of retroperitoneal haemangioma. Br J Surg 1972;59:74-6. http://dx.doi. org/10.1002/bis. 1800590121

8. Takaoka E, Yamaguchi K, Tominaga T. Cavernous hemangioma of the testis: A case report and review of the literature. Hinyokika Kiyo 2007;53:405-7.

9. Strauss DC, Hayes AJ, Thomas JM. Retroperitoneal tumours: Review of management. Ann R Coll Surg Engl 2011;93:275-80. http://dx.doi.org/10.1308/003588411X571944

10. Sethi S, Agarwal V, Chopra P. Cavernous hemangioma of the kidney: A report of twocases and review of the literature. Urol Ann 2012;4:187-90. http://dx.doi.org/10.4103/0974-7796.102674

11. Lee HS, Koh BH, Kim JW, et al. Radiologic findings of renal hemangioma: Report of three cases. Korean J Radiol 2000;1:60-3. http://dx.doi.org/10.3348/kir.2000.1.1.60

12. Yazaki T, Takahashi $S$, Ogawa Y, et al. Large renal hemangioma necessitating nephrectomy. Urology 1985;25:302-4. http://dx.doi.org/10.1016/0090-4295(85)90335-8

13. Crissey MM, Kearney GP, Sos T, et al. Renal hemangioma: diagnostic aspects and management techniques. Cardiovasc Intervent Radiol 1980;3:170-3. http://dx.doi.org/10.1007/BF02551983

14. Mundinger GS, Gust S, Micchelli ST, et al. Adult pancreatic hemangioma: Case report and literature review. Gastroenterol Res Pract 2009;839730. http://dx.doi.org/10.1155/2009/839730

15. Moody JA, Litwin MS, Cochran ST, et al. Renal cavernous hemangioma in a patient with the acquired immunodeficiency syndrome. J Urol 1996;156:1759-60. http://dx.doi.org/10.1016/S0022$5347(01) 65504-6$

16. Mallet R, Game $X$, Lefi $M$, et al. Conservative management of renal haemangioma: Value of a synergistic combination of flexible ureteroscopy and CT angiography. Prog Urol 2007;17:108-10. http://dx.doi. org/10.1016/S1166-7087(07)92237-X

17. Lin EC. Radiation risk from medical imaging. Mayo Clin Proc 2010;85:1142-6. http://dx.doi. org $/ 10.4065 /$ mcp. 2010.0260

Correspondence: Dr. Matthew Mossanen, University of Washington Medical Centre, Department of Urology, Seattle, WA, U.S.; mnmoss@uw.edu 